\title{
A CLASSE HOSPITALAR COMO INSTRUMENTO DE PARTICIPAC̣ÃO POLÍTICA NA CONSTRUÇÃO COLETIVA DA ASSOCIAÇÃO DE PAIS E PACIENTES DA HEMATO-ONCOLOGIA
}

\author{
Leodi Conceição Meireles Ortiz* \\ Simone Hoerbe Garcia** \\ Sinara Pollom Zardo*** \\ Denise Pasqual Schmidt**** \\ Sabrina Fernandes de Castro***** \\ Carina Vizzotto Meinen $* * * * *$ \\ Eliane de Oliveira Rodrigues $* * * * * *$ \\ Soraia Napoleão Freitas*
}

RESUMO: O presente artigo tem como objetivo anunciar os marcos metodológico-vivenciais da pesquisa-ação, que, como instrumento de escuta, foi registrando os sonhos, a coragem, o desejo de crescimento e a participação tecida coletivamente de informantesaprendizes movidos pela busca da garantia de direitos. Este estudo, portanto, estandardiza a principal interface da pesquisa-ação: a relação de equivalência entre o aprendizado da cidadania e as conquistas sociais.

Palavras-chave: Pesquisa-ação; Classe Hospitalar; Cidadania; Movimentos Sociais.

\section{HOSPITAL CLASS AS AN INSTRUMENT OF POLITICAL PARTICIPATION IN THE COLLECTIVE CONSTRUCTION OF AN ASSOCIATION OF BOTH PARENTS AND PATIENTS IN HEMATO-ONCOLOGY} ABSTRACT: This article is aimed to announce the methodological and experiential landmarks of a research-action. As an instrument of listening, the research has recorded the dreams, the courage and the growth of the desire, as well as the collective participation of the informant-learners, driven by the search for the rights assurance. Therefore, this study standardizes the main interface of the research-action: the equivalence relationship between citizenship learning and social achievements.

Keywords: Research-Action; Hospital Class; Citizenship; Social Movements.

\footnotetext{
* Doutoranda em Educação pela Universidade Federal de Santa Maria (UFSM); Técnica em Assuntos Educacionais junto a Universidade Federal de Santa Maria (UFSM) e Coordena o Setor Educacional / Classe Hospitalar do Hospital Universitário de Santa Maria (HUSM/UFSM). E-mail: leodiortiz@mail.ufsm.br ** Mestranda em Educação pela Universidade Federal de Santa Maria (UFSM); Educadora Especial e Especialista em Educação Especial. * * * Mestranda em Educação pela Universidade Federal de Santa Maria (UFSM) e Especialista em Gestão Educacional. **** Mestranda em Educação pela Universidade Federal de Santa Maria (UFSM) e Assistente Social do Hospital Universitário de Santa Maria (HUSM/UFSM). ${ }^{* * * *}$ Mestre em Educação pela Universidade Federal de Santa Maria (UFSM); Educadora Especial e Especialista em Educação Especial. ***** Acadêmica do Curso de Pedagogia da Universidade Federal de Santa Maria (UFSM). ${ }^{* * * * * *}$ Acadêmica do Curso de Pedagogia da Universidade Federal de Santa Maria (UFSM). ${ }^{* * * * * * *}$ Doutora em Educação pela Universidade Federal de Santa Maria (UFSM); Orientadora do projeto de pesquisa e Professora Titular/Associada do Departamento de Educação Especiaação e Inclusão Scial (GPESP) da Universidade Federal de Santa Maria (UFSM).
} 


\section{Considerações preliminares}

Com base em observações assistemáticas implementadas nas falas e ações da população de pais cujos filhos fazem tratamento de saúde no Hospital Universitário de Santa Maria (HUSM), percebeu-se um movimento crescente de mobilização reivindicatória. Tal movimento foi tomando vulto, criando adeptos e desvelando um contexto de superação. De um eixo de caráter inicialmente assistencial, promovendo melhorias na qualidade imediata da inserção dos pacientes e familiares na complexa realidade hospitalar, avançou para um eixo político, sinalizando, agora, para a busca de conquista de direitos à saúde e à vida, com a construção coletiva da Associação de Pais, Pacientes e Apoiadores da Hemato-Oncologia (APPHO).

No contexto hospitalar em que esta pesquisa-ação teve lugar, observamos que já ocorreram movimentos semelhantes, como o da Associação dos Pacientes e Amigos do Hospital-dia, fruto da mobilização de pacientes portadores do vírus HIV/AIDS, seus familiares, amigos e equipe de profissionais envolvidos no atendimento. Outro exemplo, na mesma perspectiva de trabalho, é o da Associação dos Pacientes com Distúrbio Bipolar. Tais dados confirmaram a crescente solidificação dessa tendência de organização na luta pela garantia de direitos sociais e direito de acesso às demais políticas públicas (saúde, educação, habitação, assistência, trabalho, entre outras).

Esse movimento cidadão sediado no campo da saúde não é um fato isolado e restrito à realidade local. Exemplo disso é a proliferação das Organizações Não-Governamentais (ONGs) a partir da epidemia da AIDS, que, por conter fortes rebatimentos na vida social dos indivíduos infectados (segregação, discriminação), ofereceu potencial para mobilizar grupos de indivíduos, que, "partindo de uma dada concepção sobre a epidemia, começaram a atuar em diversas frentes, oferecendo diferentes respostas", ideia esta defendida por Câmara (2000, p. 40).

Logo, o presente artigo vem ancorado na intenção de apresentar os achados desvelados no projeto de pesquisa intitulado "A classe hospitalar como instrumento de participação política na construção coletiva da Associação de Pais e Pacientes da Hemato-Oncologia", que procurou documentar o caminho escolhido por vinte pacientes adultos e pais/familiares das crianças em tratamento médico no Serviço de Hemato- 
Oncologia do Hospital Universitário de Santa Maria/RS, para o enfrentamento de suas necessidades decorrentes da permanência prolongada no espaço hospitalar, oferecendo, também, as habilidades de oito pesquisadoras e suas competências nas áreas da Educação e do Serviço Social, a se somarem às deles na constituição de sua Associação, sempre pautada pelo ideário da integração dos diferentes saberes.

Após ser determinado o campo dessa investigação, as expectativas dos interessados e o tipo de auxílio que os pesquisadores socioeducacionais puderam oferecer com a intervenção de tipo pesquisa-ação, implementou-se um estudo de viabilidades, captando apoios, sondando divergências e agrupando adesões dos sujeitos da pesquisa.

Na etapa batizada de "diagnóstico", além das prerrogativas anteriores, procedeu-se ao reconhecimento do local, à observação das características da população em questão, ao estudo sobre a natureza do "problema" coletivo a ser solucionado, à consulta a documentos e à discussão com representantes de categorias sociais a prestarem colaboração no Seminário. Diagnóstico, aqui entendido na abordagem participativa, segundo o qual equitativamente, os pesquisadores procederam à escuta sensível aos seus saberes, dos informantes e dos especialistas convidados, corporificando, assim, o legítimo processo de aprendizagem da cultura da cidadania.

Logo, o tema desta pesquisa foi explicitado em termos conceituais como: a construção coletiva da Associação de Pais, Pacientes e Apoiadores da Hemato-Oncologia e o processo formativo de cidadania implementado pela classe hospitalar do HUSM. Para tal discussão, foram buscados subsídios em áreas de conhecimento específico em Educação, Serviço Social, Direito Civil, Contabilidade e Administração Empresarial, pois a pesquisa-ação não se atém unicamente ao estatuto prático e, sim, à mediação com o teórico-conceitual.

Por ser a pesquisa-ação considerada uma abordagem não-convencional, sua marca é a dinamicidade, portanto, há que se considerar, neste estudo, o viés da transformação, a relação dos contrários, as negociações, as relações dialógicas, a tomada de consciência e as ações. Dessa forma, houve certa provisoriedade no estabelecimento de objetivos gerais, que estavam a serviço do vaivém das intenções da pesquisa.

Pela especificidade da pesquisa-ação, dois objetivos foram pontuados: 
a) Objetivo prático - Contribuir com suporte administrativotécnico-organizacional para a construção da Associação de Pais, Pacientes e Apoiadores da Hemato-Oncologia.

b) Objetivo de conhecimento - Investigar a classe hospitalar na sua dimensão sociopolítica como promotora da educação para a cidadania.

\section{Olhares epistemológicos da pesquisa-ação}

Na definição de Thiollent (1994), a pesquisa-ação é:

um tipo de pesquisa social com base empírica que é concebida e realizada em estreita associação com uma ação ou com a resolução de um problema coletivo e no qual os pesquisadores e os participantes representativos da situação ou do problema estão envolvidos de modo cooperativo ou participativo. (THIOLLENT, 1994, p. 14)

Nesta proposta de trabalho, partiu-se do pressuposto de que a investigação mediada pela pesquisa-ação transcende o alcance de objetivos de ordem puramente científica, mas, sobretudo, procura interconectar teorias às problemáticas sociais. Diante disso, a pesquisa-ação permite a inserção do pesquisador no lócus de atuação não somente como participante, mas como coadjuvante e direcionador da tarefa de procurar alternativas aos desafios cotidianos de determinada coletividade.

Considerando que a pesquisa-ação produz um elo entre o processo de investigação e a capacidade de aprendizagem do grupo envolvido, pode-se afirmar que há um princípio educativo nessa tarefa. Conforme explicita Thiollent (1994, p. 66), "As ações investigadas envolvem produção e circulação de informação, elucidação e tomada de decisões, e outros aspectos supondo uma capacidade de aprendizagem dos participantes".

Entre as características da pesquisa-ação, para Thiollent (1994), pode-se evidenciar que essa metodologia viabiliza a realização do estudo, aliando o saber formal, considerado o conhecimento dos especialistas, e o saber informal, baseado na experiência concreta dos participantes.

Sob esse prisma, a realização de uma proposta de pesquisa-ação, que buscou solucionar uma problemática social relativa aos pais e pacientes da Hemato-Oncologia do HUSM, tornou-se uma tarefa educativa for- 
madora de cidadania. Ademais, permitiu o reconhecimento do papel político e social de um ambiente educacional inserido no hospital: a classe hospitalar.

Dessa forma, considerou-se que essa investigação, que teve como cerne a comunidade e suas reivindicações, teve como essência basilar a cidadania, pois buscou constituir-se enquanto prática tradutora dos direitos e deveres desse grupo social, aliando os saberes ditos formais e informais.

Logo, supera-se a fragmentação entre senso comum e conhecimento científico advinda do paradigma do conhecimento da modernidade e busca-se aliá-los em um novo senso comum. Assim, há a necessidade de estruturar um conhecimento-emancipação, rompendo com o senso comum conservador e mistificador, sob o prisma de Santos (2002). Ainda com Santos (2002):

O conhecimento-emancipação tem de converter-se num senso comum emancipatório: impondo-se ao preconceito conservador e ao conhecimento prodigioso e impenetrável, tem de ser um conhecimento prudente para uma vida decente. (SANTOS, 2002, p. 107)

Diante desse contexto, construir um conhecimento prudente para uma vida decente, como pontua Santos (2002), diz respeito ao fato de construir os saberes a partir do silêncio instaurado na modernidade pelo poder dominador e resgatar as falas da comunidade oprimida, para então estruturar formas de organização social que primem pela qualidade de vida da coletividade. Conforme explicita o mesmo autor:

O senso comum emancipatório é um senso comum discriminatório (ou desigualmente comum, se preferirmos), construído para ser apropriado privilegiadamente pelos grupos sociais oprimidos, marginalizados ou excluídos, e, de fato, alimentado pela prática emancipatória destes. [...] É um processo sóciohistórico que começa por ser o consenso local-imediato mínimo sobre os pressupostos de um discurso argumentativo que permita identificar o colonialismo como forma específica de ignorância. A construção da emancipação neo-comunitária avança à medida que a argumentação introduz exercícios de solidariedade cada vez mais vastos. (SANTOS, 2002, p. 109)

Pensa-se que a construção de alternativas credíveis de auto-organização local, frutos da participação coletiva, seja suporte para a forma- 
ção da cidadania da comunidade envolvida na classe hospitalar, bem como dos professores que ali atuam em processo constante de formação. Nas palavras de Demo (1993, p. 23), “(...) a redução das desigualdades só pode ser fruto de um processo árduo de participação, que é a conquista, em seu legítimo sentido de defesa de interesses contra interesses adversos".

Pensando a educação como ato político e possibilidade de articular ações que visem à qualidade de vida da comunidade engajada na mudança de sua situação social, destaca-se o papel de valorização do próximo e da solidariedade como ponto de partida para a execução das mobilizações. Como Santos elenca (2002):

O conhecimento-emancipação privilegia o próximo como forma de conceber e compreender o real, mesmo que o real seja o global ou o futuro. Só a ligação à proximidade, mesmo a uma proximidade nova e desconhecida, pode conduzir ao reencantamento do mundo. (SANTOS, 2002, p. 115)

Coube aos profissionais envolvidos estabelecer as diferentes relações dialógicas que possibilitem a aproximação dos diferentes saberes, envolvendo os conhecimentos de pais, técnicos-especialistas e pesquisadores.

Historicamente, os movimentos sociais expressam as lutas sociais de diversos segmentos da população. Porém, na década de 1990, esses movimentos sociais assumem uma nova configuração. Como aponta Gohn (1998):

Nos anos 90 o cenário das ONGs cidadãs latino-americanas se altera completamente. As atenções das agências patrocinadoras de fundos de apoio financeiro e de pessoal para trabalho de base, articuladas às Igrejas, voltaram-se para os processos de redemocratização do Leste europeu. Os movimentos e as ONGs latinas passaram a viver a mais grave crise econômico-financeira desde que foram criadas. A mudança na forma de financiamento altera a atuação das ONGs. A escassez de recursos das agências de cooperação internacional, ou a mudança de seus critérios e diretrizes - agora apenas de assessoria técnica e não mais de fundos financeiros levarão à necessidade de se gerar recursos próprios e lutarem pelo acesso aos fundos públicos. (GOHN, 1998, p. 14)

Assim, hoje concebemos que todas essas organizações se modificaram, seguindo a lógica de um mercado, e se constituíram como organismos prestadores de serviço ao Estado (terceirização). Assim, essas 
ONGs não mais se colocam contra o Estado, como as da fase anterior, muito mais se colocam como parceiras, elas compõem o que tem sido denominado terceiro setor. E é ele também que tem se constituído no mercado como um dos novos espaços ocupacionais para muitas profissões que trabalham com a educação e com o social.

O trabalho de organização das associações é coerente com o compromisso ético-político, uma vez que busca a construção de espaços que visam ao fortalecimento da cidadania, por meio do exercício da participação, numa perspectiva de emancipação olhada por Fernandes (2003).

\section{Olhares aos achados da pesquisa-ação}

Embora sabedores de que a pesquisa-ação é uma modalidade que necessita de técnica preferencialmente flexível, houve uma preocupação em seguir certos balizamentos metodológicos: a) Os Seminários envolveram a participação dos principais membros pesquisadores e do grupo pesquisado; b) A representatividade dos atores da pesquisa-ação obedeceu a critérios de intencionalidade, em razão da relevância dos mesmos na discussão do tema, ou seja, houve um realce da qualidade sobre a quantidade e; c) A observação participante, o diário de campo e o formulário foram os instrumentos de coleta de dados eleitos.

$\mathrm{Na}$ perspectiva desta investigação, os dados são discutidos de forma plural, ou seja, há aproximação, na vertente de horizontalidade, entre pesquisadores, participantes e técnicos convidados, para que se proceda à interpretação dos resultados. Tal interpretação utilizou um quadro de referência teórica que lhe emprestou significado e que fomentou um processo de ensino-aprendizagem ao grupo. Dessa forma, a pesquisaação se constituiu, também, como espaço do aprender, desenvolvendo habilidades de geração e utilização de informações; diálogo argumentativo; iniciativa e autonomia; participação e conscientização; portanto, passagem do senso comum para o senso crítico e a emancipação.

A análise dos dados, a ser exposta, teve como eixo articulador os pressupostos da pesquisa-ação, que postularam a busca de soluções e a implementação de ações planejadas para a superação dos obstáculos de determinado grupo social, partindo essencialmente do trabalho participativo-coletivo. Logo, os achados do projeto foram explanados buscando 
desvelar o processo de formação cidadã gestado no ato de construção da Associação de Pais, Pacientes e Apoiadores da Hemato-Oncologia do HUSM, tendo como guia os objetivos e os referenciais teóricos que constituíram essa proposta gnosiológica.

Para instigar a discussão coletiva, foi lançada a seguinte indagação: "Para quê queremos construir a Associação?" Dessa pergunta, puderam ser destacadas algumas respostas significativas:

"Para o esclarecimento das doenças, para saber mais o que acontece com nossos filhos. Para ter maior aproximação entre o médico, mãe e paciente. Conheço casos de mães que não sabem a realidade de seu filho." (Mãe do paciente-aluno G. ${ }^{1}$ );

"Para melhorar a comunicação da equipe médica, pois eles se contradizem quando vão explicar aos pais." (Mãe da paciente-aluna V.);

"Para organizar melhor o tempo de coleta, acelerando, assim, as consultas." (Paciente C.);

"Para separar adultos e crianças no ambulatório, pois do jeito que está as crianças, principalmente as que estão com a imunidade baixa, estão sujeitas a doenças, infecções." (Pai do paciente-aluno E.).

Esses depoimentos revelaram que os participantes do projeto consideram a Associação como um instrumento de promoção na qualidade de atendimento de saúde. Dessa forma, mostraram que, por meio da implementação dessa ação coletiva, poderão reivindicar um tratamento de saúde que prime pela parceria família-equipe de saúde, pautado na comunicação e no esclarecimento das doenças que acometem seus filhos. Ademais, a construção da Associação também visou a modificações no âmbito da gestão dos serviços oferecidos pela instituição hospitalar, revelado nos discursos que sugeriram a melhor organização da coleta de sangue e do ambulatório.

Pela participação dos pais e pacientes foi possível articular um movimento que buscou a garantia dos direitos constitucionais dos sujeitos inseridos no cotidiano hospitalar do HUSM. Tal pressuposto é reafirmado com a fala do Pai do paciente-aluno E:

"A Associação em construção é importante para dar força ao movimento, uma vez que os pais já se mobilizaram anteriormente para reivindicar pequenas causas". 
Ou seja, a Associação permitiu a consolidação de ações institucionais do hospital para atendimento das necessidades da sua comunidade. Tais pressupostos demonstraram a participação coletiva como instrumento fomentador da organização da associação.

Discorrendo sobre as formas de participação, Lück (2006) afirma que ela tem sido exercida sob diferentes perspectivas, como: presença - quando o participante é membro de um grupo ou organização, independentemente de atuar nele; expressão verbal e discussão de ideias - quando discussões, diálogos e ideias existem, mas não interferem nas ações adotadas posteriormente; representação - quando um representante é escolhido para traduzir os desejos, anseios e necessidades de uma coletividade; tomada de decisão - quando a participação para tomada de decisão fica limitada a questões operacionais, e não aos significados das questões e dos desafios em si; e, por fim, participação como engajamento entendido como o nível mais pleno da participação, pressupondo a atuação conjunta como forma de superar as expressões de alienação/passividade e autoritarismo/centralização. Nas palavras da autora:

Em suma, participação como engajamento implica envolver-se dinamicamente nos processos sociais e assumir responsabilidade por agir com empenho, competência e dedicação visando promover os resultados propostos e desejados. Portanto, é muito mais que adesão, é empreendedorismo comprometido. (LÜCK, 2006, p. 47)

Destacados os pressupostos que serviram como pauta de trabalho para a organização da Associação, com base nos princípios de uma participação como engajamento. $\mathrm{Na}$ reunião, foi questionado o grupo presente sobre quais profissionais seriam convidados para participar das reuniões ou serem integrantes dessa ação. Essa proposição originou várias sugestões:

"Um advogado e uma pessoa relacionada à imprensa para divulgar a Associação." (Mãe do paciente-aluno $\mathrm{G}$.);

"Uma pessoa que tenha construido uma Associação, e também a participação de pais e pacientes que já tenham vínculo com uma Associação"... "Também seria interessante trazer um profissional da saúde para esclarecer sobre as doenças, bem como um contador para administrar o que a Associação venha a adquirir.” (M., Pai do paciente-aluno I.). 
Essas falas revelaram a necessidade da Associação, desde sua origem, de buscar articular os saberes de profissionais de diferentes áreas, a fim de consolidar bases sólidas para a implementação de suas ações para atendimento das necessidades dos usuários do serviço de HematoOncologia do HUSM.

Vale destacar que o paciente $\mathrm{C}$ ressaltou, ainda, a necessidade de a Associação não possuir vínculos políticos, o que foi acordado por todos os participantes da reunião, negando, assim, o domínio da consciência ingênua.

Ao final do encontro inicial, foi lançada uma questão-desafio que consistiu no ponto de partida da segunda reunião: "Como faremos para construir efetivamente essa Associação?” Vale destacar algumas manifestações dos participantes nos encontros, referindo-se ao processo de construção da Associação:

"Cada pessoa deve participar, mostrar interesse, independentemente de seu filho, as pessoas devem participar pelas outras crianças também, mesmo após seus filhos estarem curados. Devemos ter organização para lutar pelos nossos direitos. Não tenham vergonha de lutar pela saúde de seu filho.” (M., Pai do paciente-aluno I.);

"Dar continuidade a causa, e não olhar apenas para si." (Paciente C.).

Pode-se destacar que, na construção da Associação, houve a manifestação da dimensão política no processo de participação, ou seja, da conscientização dos participantes sobre o seu papel social na construção de uma prática que zele pelos deveres sociais e pela conquista de direitos. Remetendo-se aos comentários destacados, pode-se aliar a contribuição de Lück, ao enfatizar que:

A participação, em seu sentido pleno, caracteriza-se por uma força de atuação consciente pela qual os membros de uma unidade social reconhecem e assumem seu poder de exercer influência na determinação da dinâmica dessa unidade, de sua cultura e de seus resultados, poder esse resultante de sua competência e vontade de compreender, decidir e agir sobre questões que lhe são afetas, dando-lhe unidade, vigor e direcionamento (LÜCK, 2006, p. 29).

A partir da discussão deste encontro, a comunidade participante do projeto definiu o objetivo que devia ser pontuado no Estatuto da Associação, que diz respeito ao fato de lutar pela saúde como um direito constitucional e no Sistema Único de Saúde. 
Ao serem apresentados a todos os participantes os capítulos I, II, III, IV, V, VI e VII do Estatuto da APPAHO, procedeu-se à discussão, à modificação de alguns pontos e, posteriormente, à votação. É importante salientar que os capítulos foram aprovados com a adesão de todos os que estavam presentes. Alguns pontos foram redefinidos, como a mudança do nome da Associação de Pais, Pacientes e Amigos da HematoOncologia para Associação de Pais, Pacientes e Apoiadores da HematoOncologia. Esse ponto foi definido com 100\% de votos.

Após algumas orientações jurídicas a respeito de medicamentos e formas de ingresso com ações jurídicas, os participantes presentes demonstraram grande interesse nesse aprendizado:

"A UNIFRA está à disposição para quando as pessoas precisarem de auxílio jurídico?"... "A ideia é de formarmos a Associação para sermos melhor representados, pois estávamos sendo esquecidos e foi dessa maneira que pudemos reivindicar nossos direitos." (M., pai do aluno-paciente I.)

"As crianças têm seus direitos, é dever do SUS mandar medicamentos?" (M., mãe de aluno-paciente)

"Nós estamos sendo lesados quanto aos medicamentos e a Associação é para nos ajudar". (M., pai de aluno-paciente I.)

"A nossa Associação é para uns ajudar os outros, pois nós sabemos nossos direitos e estamos sendo lesados por burocracias e muitos não sabem como lidar com isso." (M., mãe de aluno-paciente)

"Nossa maior dificuldade é a consciência dos pais que não participam das reuniões, pois eles não sabem seus direitos." (M., pai de aluno-paciente)

Com relação à área contábil, o grande problema da Associação seria a renda não ser fixa, dificultando, assim, o planejamento.

Após os esclarecimentos, os participantes fizeram perguntas:

"Poderia ser criado um vínculo com empresas que ajudem na divulgação da Associação?"... "Temos que legalizar o mais rápido possivel o Estatuto para abrirmos a conta corrente para arrecadar fundos." (M., pai de paciente-aluno I.)

"Consigo em um jornal de circulação de Camobi para divulgar e buscar apoiadores". "Faz̧er propagandas com credibilidade, nunca enganosa.” (R., avô da paciente-aluno A.) 
"Se a pessoa não é de Santa Maria, tem como fažer a divulgação na sua cidade?" (M., pai de paciente-aluno)

"Sozinhos nós não andamos, precisamos da ajuda de todos os pais". Convocou, portanto, os pais para estarem todos na próxima reunião e participarem. (M., pai de paciente-aluno)

"Não adianta poucos quererem faẓer e a maioria não." (R., avô de paciente-aluno)

"As pessoas têm a mente tão pequena. Nós temos que conscientizar os pais. O que a gente mais ouve é que dizem que isso não vai dar em nada"... "Vamos procurar fazer do sofrimento a busca de um amanhã melhor. As pessoas têm que evoluir." (M., pai de paciente-aluno)

Cabe aqui destacar a importância da participação dos pais na efetivação da associação. Nas palavras de Souza (2006):

Participação é um dos cinco princípios da democracia. Sem ela, não é possível transformar em realidade, em parte da história humana, nenhum dos outros princípios: igualdade, liberdade, diversidade e solidariedade. (...) Em resumo, cada um de nós é responsável pelo que acontece nas questões locais, nacionais e internacionais. Somos cidadãos do mundo e, portanto, co-responsáveis por tudo o que ocorre. A única forma de transformar este direito em realidade é através da participação. (SOUZA, 2006, p. 2).

As falas dos informantes denotam o que Sacristán (2002, p. 131) referenda sobre relações de cooperação: "O apego entre os indivíduos baseia-se também na compreensão da necessidade de sua complementaridade para realizar aquilo que, por si sós, não poderiam alcançar".

"Além do Presidente e do Vice-Presidente, deveria ter mais pessoas para poder auxiliá-los, porque o Presidente e o Vice podem acabar sozinhos"...' Todos dentro da Associação vão ter o mesmo valor"... "O Presidente eleito precisa saber sua importância para resolver os problemas que irão surgir.” (M., pai de paciente-aluno)

"Devemos colocar alguém que vai representar fielmente a Associação." (E., mãe de paciente-aluno)

Levantou a questão: "baverá algum colaborador (patrocinador) que auxiliará a Associação?” (EL., mãe de paciente-aluno)

"A Associação existe para que nós lutemos pelos nossos direitos. Temos que começar a conscientizar o povo e já podemos escolher a chapa da presidência." (M., pai de paciente-aluno) 
"A chapa tem que ser composta por pessoas que sabem das nossas necessidades." (E., mãe de paciente-aluno)

Juntamente com as sugestões dos participantes, foram sendo traçadas as formas da logomarca, que ficou estabelecida como sendo um Sol nascendo e, dentro dele, pessoas, simbolizando os participantes da Associação, com a seguinte frase: "Lutando com você" e/ou "Juntos venceremos". Também foi decidido o nome-fantasia da Associação, sendo aceito por todos os presentes: "Parceiros da Hemato-Oncologia".

Nesse momento da discussão, cabe elencar os resultados quantitativos obtidos por meio do instrumento de pesquisa, o formulário, e tendo como informantes vinte pais e pacientes, todos do Rio Grande do Sul, que participaram da Associação. Com base nesses dados, foi possível traçar o perfil dos participantes:

Figura 1: Vínculo familiar com o paciente.

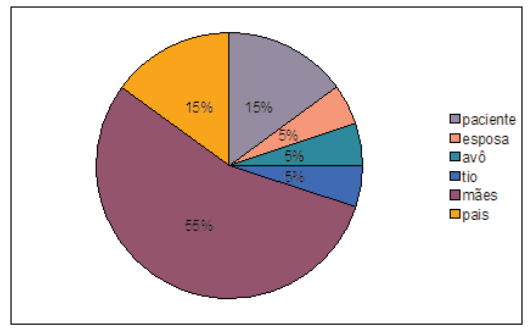

Figura 2: Sexo dos participantes da pesquisa.

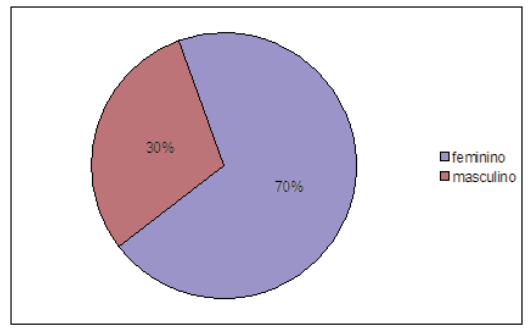


Figura 3: Grau de instrução dos participantes da pesquisa.

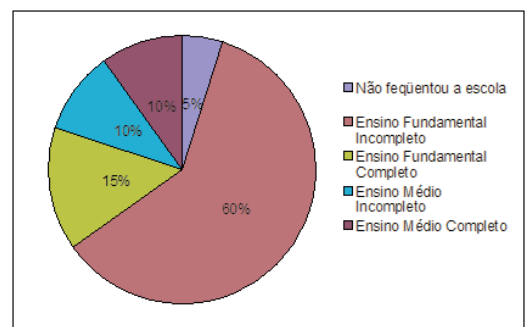

Figura 4: Localização das residências na área municipal.

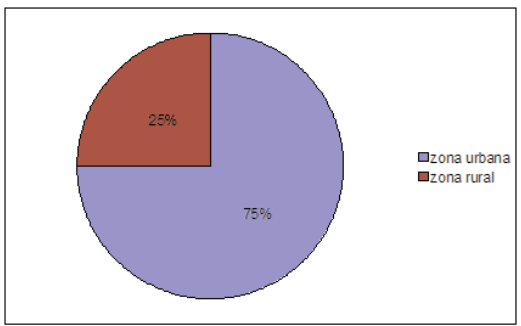

Figura 5: Tempo de vinculação no HUSM em decorrência do tratamento médico.

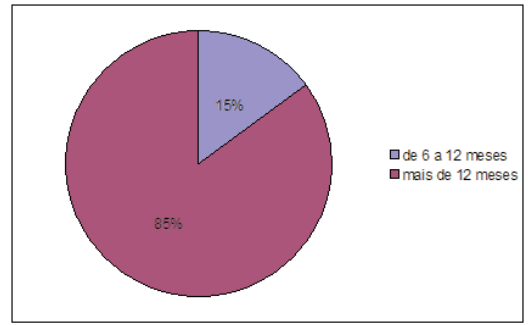

Figura 6: Participação em associaç̃ões comunitárias.

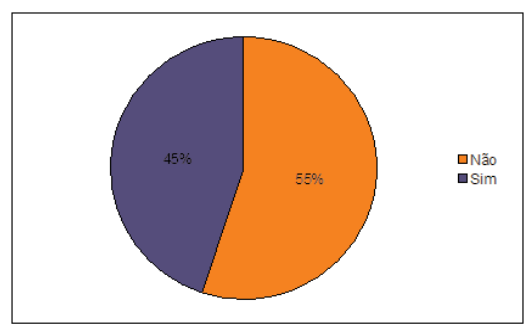

Sendo que desses 45\% participantes de associações, destacam-se os locais de atuação: 
Figura 7: Tipos de associações comunitárias.

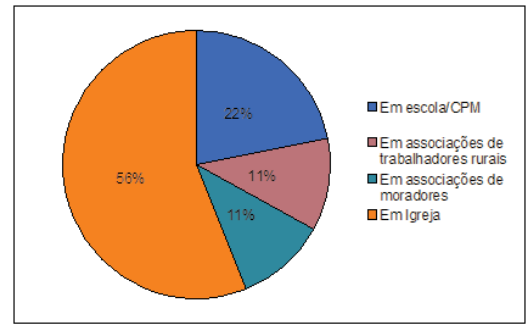

Dois informantes não exerceram função específica na associação de que participaram. Os demais respondentes exerceram, cada um, funções diferenciadas de vice-presidente, fiscal de compras, fiscal, conselheiro, catequista, recreacionista e líder/conselheiro fiscal.

Pode-se inferir que a maioria dos participantes tem seus filhos ou faz tratamento de saúde no Hospital Universitário de Santa Maria (HUSM) há mais de dois anos, ou seja, trata-se de uma população sabedora das deficiências do hospital. A maioria das pessoas não participou de outro tipo de Associação, o que nos fez perceber que o processo participativo nessa atividade aguçou o senso crítico e o conhecimento de seus direitos e deveres, que se fizeram cada vez mais explícitos à medida que as reuniões do projeto avançavam, pois a construção da associação foi feita de forma coletiva, com a participação efetiva de todos. Tal participação é movida por desejo de liberdade, não no viés de doação, favorecimento ou dominação, mas, antes, sonhada e construída por suas identidades. De certa forma, concretizando as conceituações de Demo (1993, p. 18), "participação é conquista para significar que é um processo, (...) infindável, em constante vir-a-ser, sempre se fazendo (...) não pode ser estendida como dádiva, como concessão, como algo já preexistente”. A exemplo disso, tivemos a elaboração do estatuto da Associação, trabalho extenso e cansativo, durando três reuniões consecutivas, mas que obteve grande ganho para a instituição, pois, com a organização e a colaboração de todos os participantes que consultaram, estudaram e discutiram outros estatutos, sempre mediados pelos pesquisadores, chegou-se ao resultado final, que foi a construção do Estatuto Social da Associação de Pais, Pacientes e Apoiadores da Hemato-Oncologia.

Outro resultado obtido foi a mobilização dos participantes para eleger o Conselho Administrativo. A eleição contou com a presença de 
grande número de associados, o que mostrou o processo de conscientização e socialização desses cidadãos ao elegerem seus representantes.

A decisão em acompanhar tal processo eleitoral foi coroada com a presença espontânea dos associados no momento do escrutínio dos votos. O comparecimento deveu-se ao fato de os pais e pacientes, a partir da caminhada educativa, apropriarem-se dos conceitos de autonomia, participação, emancipação e bem comum, portanto, já se reconhecendo como "grupo". Essa argumentação está respaldada em Sacristán (2002, p. 130-131), para quem: “Concebermo-nos todos como integrantes de uma comunidade política que nos iguala não é uma experiência ou aprendizagem que se costume alcançar de forma natural. Requer ser provocado e fortalecido a partir da educação (não só a escolar)".

\section{Considerações finais}

O tema sobre o qual a pesquisa versou diz respeito ao olhar sobre a dimensão política e cultural da classe hospitalar, que se incumbe da propagação do ensino tanto via crianças - educação escolar - quanto via coletividade - educação cidadã.

Nesse momento, pontua-se que a proposta de trabalho pretendeu aliar duas causas: a dos pais, como possibilidade de reivindicação de direitos e efetivação de objetivos, e a dos pesquisadores, como possibilidade de promover uma experiência diferenciada de pesquisa, a pesquisaação, constituindo um meio de formação continuada e um desafio na busca pela concretização de ações político-educacionais em ambiente de ensino hospitalar.

Considerando a educação como um processo essencialmente político e social, buscou-se viabilizar a construção da Associação de Pais, Pacientes e Apoiadores da Hemato-Oncologia do Serviço de HematoOncologia/HUSM, pela integração dos diferentes saberes que compõem a equipe multidisciplinar para, assim, auxiliar na efetivação do trabalho educacional da classe hospitalar.

Tal pesquisa tornou-se relevante para a Universidade Federal de Santa Maria e para a comunidade regional, uma vez que possibilitou não apenas a participação dos acadêmicos dos cursos de licenciatura que atuam em contexto hospitalar, mas também aproximou profissionais das 
áreas de educação hospitalar, serviço social e saúde a partilharem saberes e ações em prol da construção de uma postura emancipatória e comunitária.

Assim, o projeto produziu conhecimento, habilitou e fortaleceu os participantes envolvidos a colocarem-se de maneira autônoma para fazer frente às demandas decorrentes da doença e da hospitalização prolongada, bem como possibilitou uma forma de organização que garantisse os direitos e deveres civis da população que usufrui e necessita desses serviços de saúde.

A pesquisa-ação, comprometida com a verdade do ato de participação, comunga com as aspirações que negam veementemente as sombras da dominação, dos democratismos, dos centralismos, dos populismos, dos purismos e dos assistencialismos, para firmar bandeira na luminosidade presentificada na emancipação e no respeito ao lugar do bom senso plural.

Dessa forma, pensa-se que a construção de alternativas credíveis de auto-organização local, fruto da participação coletiva, seja suporte para a formação cidadã da comunidade envolvida na classe hospitalar e dos professores que ali atuam em processo constante de formação.

Partindo desse pressuposto, considerou-se que o trabalho, realizado por meio da construção da Associação de Pais, Pacientes e Apoiadores da Hemato-Oncologia, contribuiu para o desenvolvimento da criticidade e da autonomia de cada participante, uma vez que oportunizou a participação coletiva nas tomadas de decisões, bem como mobilizações e mudanças que possibilitaram a real construção da Associação. Nesse sentido, entendendo a educação como ato de transformação e possibilidade de articular atitudes que visem à qualidade de vida da comunidade engajada na mudança de sua situação, destaca-se o papel de valorização do próximo, da cooperação e da solidariedade como ponto de partida para a execução de novos fazeres sociais.

Finalizando este arrazoado, chega-se à evidências de que a educação, dentro do universo de significados que assume na ambiência da saúde, é um motor movido pela utopia da mudança, impulsionando o destino do sujeito e da sociedade, bem como fazendo uso de combustível ativado pela luta dos contrários e negociações em engrenagens dialógicas, reafirmando-se, portanto, num prisma epistemológico, o papel social da educação e da pesquisa como ideário cultural da cidadania e da identidade social. 


\section{Notas}

${ }^{1}$ Com objetivo de manter a privacidade dos participantes da pesquisa, serão referidos os nomes apenas pelas letras iniciais.

\section{Referências bibliográficas}

ABONG. Direitos humanos, cidadania e AIDS. Cadernos ABONG, São Paulo, n. 28, outubro, 2000.

ABONG. ONGs identidade e desafios atuais. Cadernos $A B O N G$, São Paulo, n. 27, maio, 2000.

BRASIL. Política Nacional de Educação Especial. Brasília: MEC/SEESP, 1994. Disponível em: <www.planalto.gov.br/legislação>. Acesso em: 10 abr. 2006.

BRASIL. Diretrizes Nacionais para a Educação Especial na Educação Básica. Secretaria de Educação Especial - MEC/SEESP, 2001. Disponível em: <www.planalto.gov.br/legislação>. Acesso em: 10 abr. 2006.

BARBIER, René. A pesquisa-ação. Brasília: Liber Livro Editora, 2004.

BROSE, Markus (Org). Metodologia participativa: uma introdução a 29 instrumentos. Porto Alegre: Tomo Editorial, 2001.

DEMO, Pedro. Participação é conquista: noções de política social participativa. 2 ed. São Paulo: Cortez, 1993.

FERNANDES, Rosa M. Castilhos. Serviço Social contemporâneo. Cadernos Universitários, Canoas, n. 71, ULBRA, 2003.

FREIRE, Paulo. Pedagogia da autonomia: saberes necessários à prática educativa. 2 ed. São Paulo: Paz e Terra, 1997.

GATTI, Bernadete Angelina. Grupo focal na pesquisa em ciências sociais e humanas. Brasília: Liber Livro Editora, 2005.

GIL, Antonio Carlos. Como elaborar projetos de pesquisa. 3 ed. São Paulo: Atlas, 1991.

GOHN, Maria da Glória. O novo associativismo e o terceiro setor. Revista Serviço Social e Sociedade, n. 58, novembro, 1998.

IAMAMOTO, Marilda V. O Serviço Social na contemporaneidade: trabalho e formação profissional. 5 ed. São Paulo: Cortez, 2001.

LÜCK, Heloísa. A gestão participativa na escola. Petrópolis: Vozes, 2006.

SACRISTÁN, J. Gimeno. Educar e conviver na cultura global: as exigências da cidadania. Porto Alegre: Artmed, 2002.

SANTOS, Boaventura de Souza. Para um novo senso comum: a ciência, o direito e a política na transição paradigmática. São Paulo: Cortez, 2002.

SILVA, Jefferson Ildefonso da. Formação do educador e educação política. São Paulo: Cortez: Autores Associados, 1992.

SOUZA, Herbert. Participação. Disponível em: <http://www.mre.gov.br/cdbrasil/itamaraty/web/port/polsoc/partic/apresent/apresent.htm $>$.

THIOLLENT, Michel. Metodologia da pesquisa-ação. 6 ed. São Paulo: Cortez, 1994.

VÍCTORA, Ceres Gomes (Org). Pesquisa qualitativa em saúde: uma introdução ao tema. Porto Alegre: Tomo Editorial, 2000. 
Endereço para correspondência: Universidade Federal de Santa Maria Centro de Ciências da Saúde - Hospital Universitário Campus Universitário - Setor Educacional Classe Hospitalar - sala 18 - Térreo - Ala I

Camobi

97105-900

Santa Maria - RS

Data de recebimento: 05/06/2007

Data de aprovação: 10/11/2009 
